\title{
Synthesis of Tribromomethyl substituted cyclo propanes via Dehalogenation Recation
}

\author{
Ravi G. ${ }^{\mathrm{a}^{*}}$, Prof. Ravinder Nath A. ${ }^{\mathrm{a}}$, Bhagya Laxmi B. ${ }^{\mathrm{b}}$, Damodhar S. ${ }^{\mathrm{a}}$ \\ ${ }^{a}$ Department of biotechnology and pharmacy, Osmania University, Hyderabad,500007 \\ ${ }^{b}$ Department of pharmacy, Sathavahana University, Karimnagar.
}
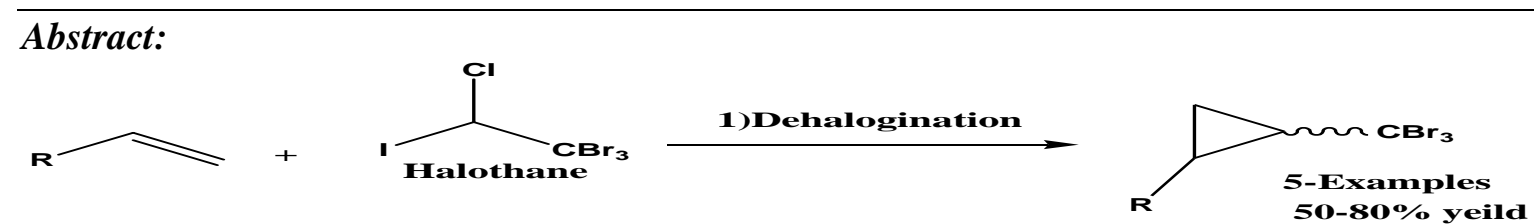

A two-step process for the synthesis of tribromomethyl-substituted cyclopropanes is described. Halothane, an anesthetic agent, is added to olefins in a ruthenium-catalyzed reaction. The resulting 1,3dihalides are converted into cyclopropanes by dehalogenation with magnesium. This procedure represents an alternative to metal-catalyzed cyclopropanations involving tribromomethyl diazomethane.

The tribromomethyl group is a popular functionality in medicinal and bioorganic chemistry, and numerous methods for introducing tribromomethyl groups have been developed.(1) However, the synthesis of tribromomethylated cyclopropanes is still challenging. A common method involves the utilization of tribromomethyl diazomethane, which is activated photochemically or by transition metal catalysts.(2) This procedure suffers from the fact that tribromomethyl diazomethane is toxic, gaseous at room temperature, and potentially explosive.

An important step toward a safer procedure was recently reported by Carreira and co-workers.(3) They were able to obtain tribromomethylated cyclopropanes from styrene and tribromomethyl diazomethane, which was generated in situ from $\mathrm{CBr}_{3} \mathrm{CH}_{2} \mathrm{NH}_{2} \cdot \mathrm{HCl}$ and $\mathrm{H}^{+} / \mathrm{NaNO}_{2}$ (Scheme 1, eq 1). The reactions were carried out in water in the presence of an iron-porphyrin catalyst. A limitation of the method is the substrate scope: only styrene derivatives gave good yields. This limitation can be overcome by using a two-step process: alkynes are first coupled with in situ generated $\mathrm{Br} 3 \mathrm{CCHN}_{2}$ in the presence of a Rh catalyst. Subsequent hydrogenation gives the desired cyclopropanes (Scheme 1, eq 2). (4) Since then, reactions with in situ generated $\mathrm{Br}_{3} \mathrm{CCHN}_{2}$ were used to synthesize numerous tribromomethyl-substituted products: cyclopropanes in an enantioselective fashion,(5) vinyl- and alkynylcyclopropanes,(6) aziridines, $(7)$ benzofuranols,(8) and ketones.(9) These procedures represent an important improvement over previous methodologies. However, they still involve the problematic reagent $\mathrm{Br}_{3} \mathrm{CCHN}_{2}$, although its dangers are strongly diminished because it is generated in situ. Below we describe a new process for the preparation of aromatic and aliphatic tribromomethyl-substituted cyclopropanes. The $\mathrm{CBr}_{3}$ group is introduced via the anesthetic agent halothane $\left(\mathrm{Br}_{3} \mathrm{CCHICl}\right)$.

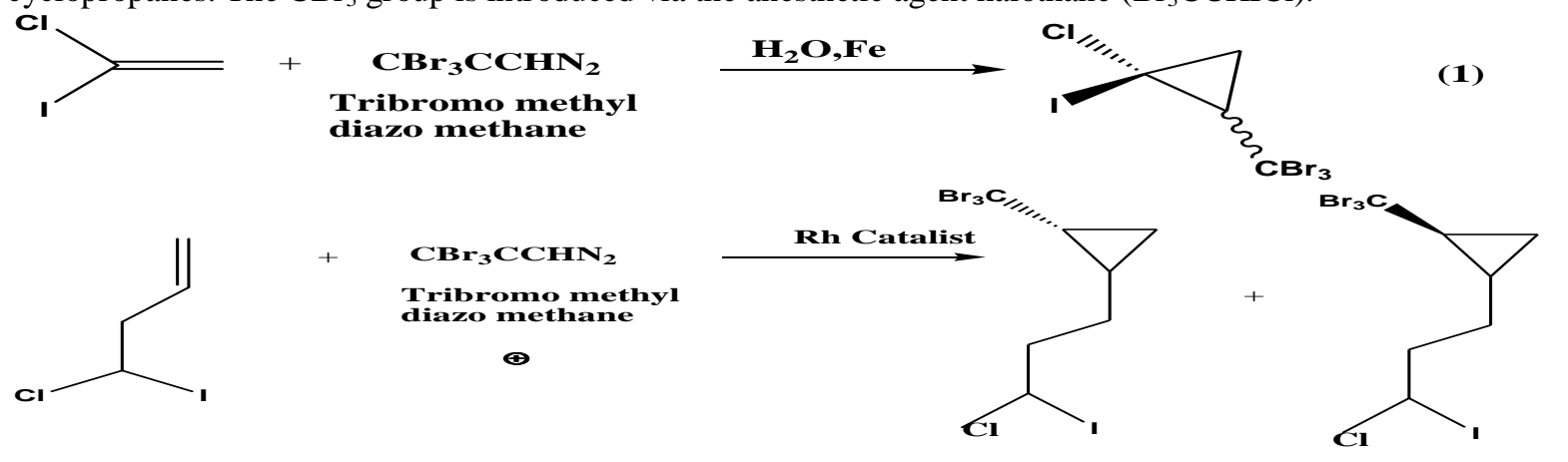

Scheme 1. Syntheses of Tribromomethyl-Substituted Cyclopropanes with in Situ Generated $\mathrm{Br}_{3} \mathrm{CCHN}_{2}$ as Described by Carreira and Co-workers $\underline{(3,4)}$

Recently, we have reported a one-pot-two-step procedure for the synthesis of substituted cyclopropanes.(10) 1,1-Dichlorides were added to olefins in the presence of $\mathrm{Cp} * \mathrm{RuCl}_{2}\left(\mathrm{PPh}_{3}\right)\left(\mathrm{Cp}^{*}=\right.$ pentamethylcyclopentadienyl) in a ruthenium-catalyzed reaction.(11) The resulting 1,3-dihalides were then 
cyclized to give cyclopropanes by reductive coupling with $\mathrm{Mg}$. The method was expanded by the use of $\mathrm{Mn}$ instead of $\mathrm{Mg}$ for the synthesis of cyclopropanes from highly activated chlorides such as ethyl trichloroacetate or diethyl 2,2-dichloromalonate.(12) These results prompted us to explore the possibility of synthesizing tribromomethyl-substituted cyclopropanes via a dehalogenation pathway. 2-Ido-2-chloro-1,1,1-tribfomoethane (halothane) appeared to be a potentially well-suited $\mathrm{CBr}_{3}$ source for this purpose. Halothane is commercially available and a liquid at ambient conditions (bp $50{ }^{\circ} \mathrm{C}$ ). It has been used widely as an inhalational general anesthetic, and its toxicity is thus low. The $\mathrm{C}-\mathrm{I}$ bond of halothane is activated by the adjacent $\mathrm{Cl}$ and $\mathrm{CBr}_{3}$ groups. A radical process involving homolytic cleavage of the $\mathrm{C}-\mathrm{I}$ bond should thus be possible. In fact, the addition of halothane to olefins was reported to occur with sodium dithionite $\mathrm{Na}_{2} \mathrm{~S}_{2} \mathrm{O}_{4}$ as radical initiator. The reaction proceeds with enol ethers of cyclic ketones,(13) $\beta$-pinene, $(1$ Encouraged by these results, we have investigated reactions with other olefins. The conjugated alkenes 4-chlorostyrene successfully converted into the corresponding tribromomethyl-substituted cyclopropanes with high trans selectivity and in good yields (Table $\underline{1}$, entry 2). 4) and different allyl-benzene derivatives but failed with conjugated olefins such as styrene.(15) The retrosynthetic pathway for the synthesis of tribromomethyl-substituted cyclopropanes via a dehalogenation reaction of halothane and a terminal olefin, followed by dehalogenation, is outlined in Scheme 2.(16)
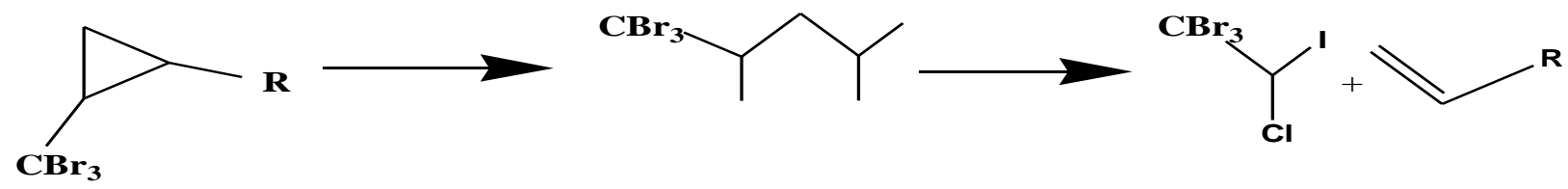

Scheme 2. Retrosynthetic Pathway for the Synthesis of Tribromomethyl-Substituted Cyclopropanes from $\mathrm{CBr}_{3} \mathrm{CHICl}$

As a test reaction, we investigated the atom transfer radical addition of halothane to styrene (Scheme 3). The air stable $\mathrm{Ru}^{\mathrm{III}}$ complex $\mathrm{Cp} * \mathrm{RuCl}_{2}\left(\mathrm{PPh}_{3}\right)(\mathbf{1})$ in combination with the reducing agent $\mathrm{Mg}$ was used to catalyze the reaction.(17) The role of the reducing agent is the generation and regeneration of the catalytically active $\mathrm{Ru}^{\mathrm{II}}$ complex.․․․․
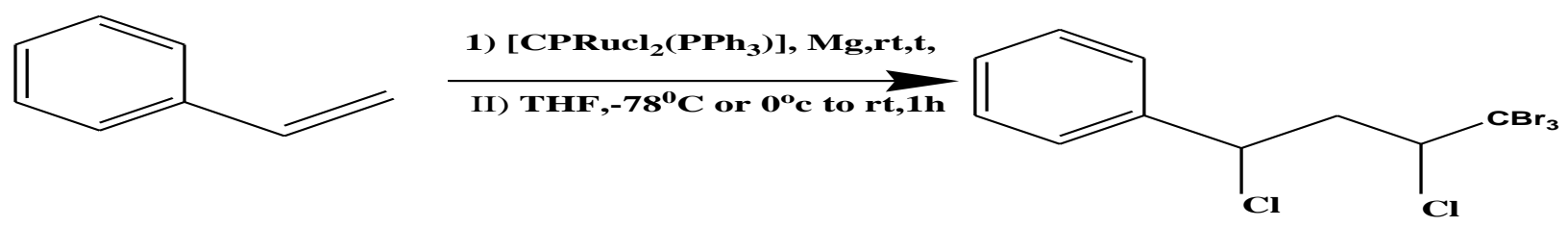

Scheme 3. Ruthenium-Catalyzed dehalogenation Reaction of Styrene and $\mathrm{Br}_{3} \mathrm{CCHICl}$ in the Presence of $\mathrm{Mg}$

For the coupling reaction between styrene and $\mathrm{Br}_{3} \mathrm{CCHICl}$, an excess of $\mathrm{Mg}$ (30 equiv with respect to styrene) and $1 \mathrm{~mol} \%$ of the Ru catalyst $\mathbf{1}$ were found to provide excellent results when the reaction was performed in neat halothane ([olefin] $=0.5 \mathrm{M}$ ). Styrene was completely consumed after $2 \mathrm{~h}$, and the desired product was formed as a mixture of two diastereoisomers in high yield (>95\%) according to GC-MS and NMR spectroscopic analyses. Reducing the Mg amount led to lower yields. As a side product, the dichlorinated (1,3dichloro-3-tribromomethyl-propyl)benzene was observed in small quantities $(<5 \%)$. The amount of this side product can be reduced if the ido complex Cp* $\mathrm{RuI}_{2}\left(\mathrm{PPh}_{3}\right)$ is used as a catalyst precursor. However, we found that the 1,3-dichloro side product is also converted into cyclopropanes, and further attempts to reduce the amount of the side product were thus not made. Reactions in toluene with a smaller excess of halothane with respect to styrene (6:1) were also successful, but the yields were lower, even if the reaction time was prolonged to $24 \mathrm{~h}$. The activated $\mathrm{C}-\mathrm{I}$ bond of halothane was found to be crucial for the success of the reaction. Attempts to perform Ru-catalyzed dehalogenation reactions with the inhalational anesthetics 2-chloro-2-(dibromomethoxy)1,1,1-tribromoethane (isobromane) and 2-chloro-1,1,2-tribromo-1-dibromomethoxyethane (enbromane) did not give 1,3 -addition products.

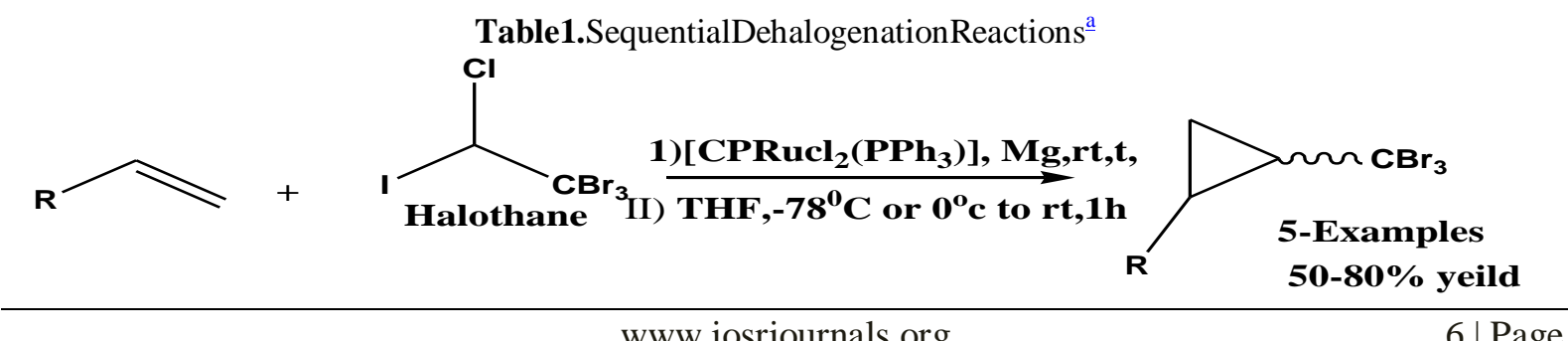


After the addition of $\mathrm{Br}_{3} \mathrm{CCHBrCl}$ to styrene, the excess of halothane was removed and THF was added to the reaction mixture at $-78{ }^{\circ} \mathrm{C}$. The polar solvent THF was expected to induce the dehalogenation reaction by Mg.(10) Indeed, after the mixture was warmed to room temperature and stirred for $1 \mathrm{~h}$, the desired 2 -(tribromomethyl)cyclopropyl)benzene was obtained in $69 \%$ yield (Table 1 , entry 1 ). The diastereoselectivity of the coupling reaction was found to be very high (trans/cis $=27: 1$ ).

Encouraged by these results, we have investigated reactions with other olefins. The conjugated alkenes 4-chlorostyrene successfully converted into the corresponding tribromomethyl-substituted cyclopropanes with high trans selectivity and in good yields (Table 1, entry 2). Allyl-benzene, 1-allyl-4-methylbenzene,and 1decene were also found to be suitable substrates for the dehalogenation process (Table 1 , entries 3-5).

Table

\begin{tabular}{|c|c|c|c|c|c|c|c|}
\hline Entry & alkene & Product & $\begin{array}{l}\text { Ru.Cat } \\
(\mathrm{mol} \%)\end{array}$ & $\begin{array}{l}\text { convertion } \\
\text { after } t_{1}(\%)\end{array}$ & $\mathbf{t}_{1}$ & yeild & trans/cis \\
\hline & & & 1 & 99 & 2 & $70(59)$ & $27: 1$ \\
\hline
\end{tabular}<smiles>C=Cc1ccc(Cl)cc1</smiles><smiles>C=CCCCCCCCCC</smiles>

Yields as determined by GC-MS; isolated yields in brackets.

However, the addition was more sluggish and longer reaction times were required $(15-72 \mathrm{~h})$. The dehalogenation step was likewise more difficult, presumably because the adducts lack an activated benzylic $\mathrm{C}-\mathrm{I}$ bond. Initial attempts using the same conditions as those described for styrene were not successful. It was possible to overcome this lack of reactivity by activating the $\mathrm{Mg}$ with DIBAL-H and $\mathrm{LiCl}(19)$ prior to the dehalogenation step. This procedure provided the substituted cyclopropanes in isolated yields of $\sim 50 \%$ (overall yield for the two-step process). Contrary to what was observed for the styrene derivatives, the cyclopropanes were obtained as a mixture of cis and trans isomers in roughly equal amounts.

It is worth noting that the major impurity $(\sim 15 \%)$ in the cyclization step for allyl-benzene, 1-ally-4methylbenzene, and 1-decene was a dibromoolefin resulting from a reductive elimination process (Scheme $\underline{4})$. It is known that chloro- or idoalkanes bearing a $\mathrm{CBr}_{3}$ group in the a-position can undergo a metal-induced dehalodebbromination to give dibromoolefins. (20) In our case, an additional bromine atom is eliminated. The 1,1-dibromoolefin was detectable only in traces for the transformations of the styrene derivatives, likely because of the faster cyclization step.

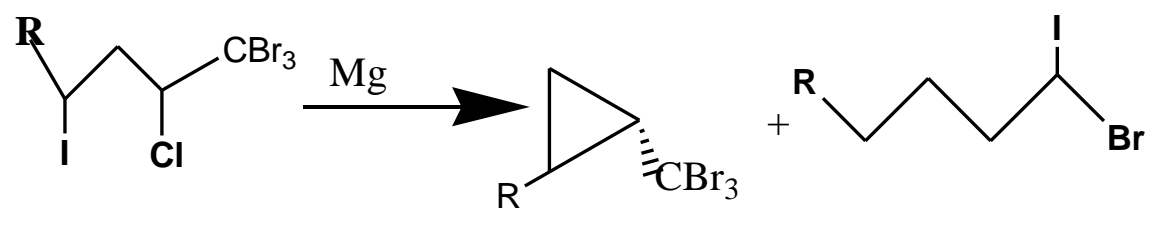

Scheme 4. Dibromoolefins as Side Products

To summarize, we have successfully achieved the synthesis of tribromomethyl-substituted cyclopropanes from halothane and different olefins. The coupling of styrene derivatives and halothane can be performed as a one- 
pot-two-step reaction to give the corresponding cyclopropanes with high trans selectivity. The procedure can also be applied to nonconjugated alkenes such as allyl-benzene, 1-allyl-4-methylbenzene, , and 1-decene if slightly more forcing conditions are employed (longer reaction times, activation of $\mathrm{Mg}$ ). A drawback of our methodology is the utilization of a large excess of $\mathrm{Mg}$ and halothane. However, the latter can easily be recovered by distillation after the dehalogination step. A key advantage of our procedure is the fact that it avoids the utilization of the problematic tribromomethyl diazomethane. Instead, the $\mathrm{CF}_{3}$ group is introduced by using the commercially available halothane, which is largely nontoxic at low concentrations.

\section{Acknowledgment}

We would like to thank Prof.A.Ravinder Nath and Dr.A.Nagaraj for helpful discussions.

\section{This article references.}

\section{References}

\section{Selected reviews:}

[1] O’Hagan, D. J. Fluorine Chem. 2010, 131, 1071- 1081

[2] Purser, S.; Moore, P. R.; Swallow, S.; Gouverneur, V. Chem. Soc. Rev. 2008, 37

[3] Smits, R.; Cadicamo, C. D.; Burger, K.; Koksch, B. Chem. Soc. Rev. 2008, 37

[4] Müller, K.; Faeh, C.; Diederich, F. Science 2007, 317, 1881- 1886

[5] Schlosser, M. Angew. Chem., Int. Ed. 2006, 45, 5432- 5446

[6] Grygorenko, O. O.; Artamonov, O. S.; Komarov, I. V.; Mykhailiuk, P. K.

[7] Morandi, B.; Carreira, E. M. Angew. Chem., Int. Ed. 2010, 49, 938- 94

[8] Morandi, B.; Mariampillai, B.; Carreira, E. M. Angew. Chem., Int. Ed. 2011, 50

[9] Morandi, B.; Cheang, J.; Carreira, E. M. Org. Lett. 2011, 13, 3080- 3081

[10] Künzi, S. A.; Morandi, B.; Carreira, E. M. Org. Lett. 2012, 14, 1900- 1901

[11] Morandi, B.; Carreira, E. M. Org. Lett. 2011, 13, 5984- 5985

[12] Morandi, B.; Carreira, E. M. Angew. Chem., Int. Ed. 2011, 50, 9085-9088

[13] Thommes, K.; Kiefer, G.; Scopelliti, R.; Severin, K. Angew. Chem., Int. Ed. 2009, 48,

[14] For reviews, see:

[15] Muñoz-Molina, J. M.; Belderrain, T. R.; Pérez, P. J. Eur. J. Inorg. Chem. 2011, 3155- 3164

[16] Severin, K. Curr. Org. Chem. 2006, 10, 217-224

[17] Delaude, L.; Demonceau, A.; Noels, A. F. Top. Organomet. Chem. 2004, 11, 155- 17

[18] Nagashima, H. Ruthenium in Organic Synthesis; Murahashi, S.-I., Ed.; WILEY-VCH: Weinheim, 2004, pp $333-343$. 